\title{
EL ALUMBRE MURCIANO
}

\author{
Por \\ ALFONSO FRANCO SILVA \\ Colegio Universitario de Filosofía y Lotras \\ Cádiz
}




\section{INTRODUCCION}

Cuando nos encontrábamos estudiando la formación del marquesado de los Vélez topamos con varios legajos cuyos documentos tenían un único objeto, el comercio y la producción del alumbre murciano. Dada la información que proporcionaban decidimos meternos de lleno en el asunto, aún a sabiendas de lo espinoso que podía resultar. Las páginas que a continuación siguen pretenden únicamente aportar una serie de noticias más o menos inéditas sobre esta materia prima de enorme importancia para la industria textil medieval, porque como moraiente fijaba los colores en las telas, además de usarse en otros menesteres (1).

La historia de este producto ha sido muy marginada por la investigación. Salvo el excelente trabajo de J. Delumeau sobre el alumbre pontificio y el estudio tan esperado de Felipe Ruiz Martín y que nunca se

(1) Se empleaba también en el curtido de cueros y pieles, en la iluminación de códices y en la elaboración de vidrios y pergaminos. Miguel Gual Camarena: Vocabulario del Comercio Medieval, Tarragona, 1968, pág. 202. Sobre los usos del alumbre Jean Delumeav: L'alun de Rome. XV.XIX siecle, Paris, 1962, págs. 13-18. 
ha dedicido a publicar, pocas son las noticias que hemos hallado sobre los alumbres españoles (2). Por otra parte la documentación conservada en el Archivo Ducal de Medina Sidonia tiene lagunas apreciables, apenas si hay datos de salarios de los obreros, de la vida en las pedreras. Nada nos dice sobre los beneficios que reportaba el mineral a los arrendadores y desconocemos también las cantidades que no eran objeto de exportación. Pero en conjunto es lo suficientemente coherente y nos suministra los datos necesarios para hacernos una idea de lo que fue la evolución de este negocio desde el comienzo de la explotación hasta el cierre de las minas. Así, pues, este trabajo tiene como objetivo seguir un poco la pista del alumbre murciano hasta donde nos han permitido conocerla los documentos manejados.

\section{LOS COMIENZOS DE LA EXPLOTACION}

El descubrimiento de las minas de Tolfa en los Estados Pontificios en torno a 1462 coincidió con la apertura de las de Mazarrón en Murcia (3). Delumeau ha trazado un cuadro completísimo de la producción de las minas Pontificias a lo largo del Antiguo Régimen relacionándolas con las castellanas y describiendo con gran minuciosidad los contratos que los Papas establecieron con los Médicis y después con los genove-

(2) El estudio antes citado de Delumeau es el mejor trabajo que se ha hecho hasta ahora sobre este producto. El libro de FELIPE RUIz MARTIN titulado Les Aluns tispagnols no se ha publicado aún, pero Delumeau llegó a ver una copia mecanografiada que es lo que nosotros conocemos a través del historiador francés. Otros trabajos sobre el alumbre o que se refieren indirectamente a él son los siguientes: JACOUES HeERS: Lcs Italiens et l'Orient Méditerranéen d la fin du Moyen Age, aVI Congreso de Historia de la Corona de Arag6n. Madrid, 1959, págs. 697-800; HenRY LAPEYRE y RAMON CARANDE: Relaciones comerciales en el Mediterraneo durante el siglo XVI, Madrid, 1957, 112 págs.; Marfa LuISA Haprs: Les Genois et le commerce de l'alun d la fin du Moyen Age, aRevue d'Histoire Economique et Sociale» (Paris), XXXII, 1954, págs. 31-53; RAMÓN CARANDE: Carlos $V$ y sus banqueros, tomo II, Madrid, 1949, págs. 352-356.

(3) J. Delumau: op. cit., pág. 20. Existe una gran discusión en torno a la fecha exacta del descubrimiento de las minas papales. Nosotros hemos seguido la opinión de Delumeau a quien consideramos el autor más documentado sobre este asunto. 
ses (4). El hallazgo de ambos alumbres resultó providencial en unos momentos en que Europa sentía verdadera necesidad de este mineral para la industria textil flamenca ante el encarecimiento en que la habian puesto los turcos. La forma de explotar las minas romanas fue la misma que la llevada a cabo en las de Edesa en el Asia Menor, de donde primordialmente se extraía el alumbre antes del descubrimiento de las de Tolfa; coincidirá también con las que aquí nos ocupan (5).

Una vez descubierto el alumbre sólo el monarca podía disponer de él en virtud de gozar de la regalía de todas las minas del reino. Sin embargo Enrique IV concedió de inmediato todo el alumbre murciano a su favorito don Juan Pacheco, marqués de Villena, por cédula real dada en Madrid el 24 de mayo de 1462 (6). El débil monarca no comprendió la importancia que para la hacienda de la Corona suponía el nuevo descubrimiento, al contrario del Papado que desde el primer momento se percató de los grandes beneficios que podría reportarle la explotación de tan preciado producto (7). De esta manera la Corona se desprendía un tanto irresponsablemente de una importantísima fuente de ingresos en el futuro. Pocos días más tarde de esta concesión regía, el 27 de ese mismo mes, Villena cedió al Adelantado de Murcia, Pedro Fajardo, la mitad del derecho que tenía a todas las minas de ese reino en virtud de la merced anterior y lo hacía así apor algún amor e debdon que tenía con su primo (8). Enrique IV confirmó y aprobó esta cesión en Madrid €l 5 de diciembre de 1463 (9). De esta forma ambas familias, Villena y Fajardo, conseguían para sí y para sus herederos todas las minas de alumbre descubiertas y por descubrir de todo el reino de Murcia. En

(4) Delumeau: op. cit., págs. 38 y ss.

(5) Delumeau: op. cit., págs. 13 y 18.

(6) Archivo Ducal Medina Sidonia (En adelante A.D.M.S.). Legs. 33 y 570. JUAN TORRES FonTEs: Estudio sobre la Crónica de Enrique IV del doctor Galindez de Carvajal, Murcia, 1946, págs.492-497. PILAR LEON Tello: Inventario del Archivo de los Duques de Frias. II. Casa de Pacheco, Madrid, 1967. Documento n. 1.699. 1463, diciembre, 5, Madrid. Copia autorizada de 1601.

(7) Delumeau: op. cit., pág. 24, citando a Felipe Ruiz Martin: op. cit. pág. 30.

(8) A.D.M.S. Legs. 33 y 570. TORRES FonTES: op. cit., págs. $492-497$.

(9) A.D.M.S. Legs. 33 y 570. 
verdad esta donación fue arrancada al monarca por su favorito Villena como un nuevo paso adelante en la política ambiciosa de este personaje, aprovechándose de la debilidad de un Enrique IV, cada vez más necesitado de apoyos para hacer frente al sector de la nobleza rebelada contra él. Al encontrarse estas minas en Murcia, Pacheco, para asegurarse el concurso y apoyo del Adelantado, personaje poderoso y sin el cual difícilmente le hubiese sido posible conservar la jugosa donación, pactó con él la entrega de la mitad de sus derechos a ellas. Muerto Enrique IV y triunfante ya Isabel I, el hijo de Villena obtuvo de esta última nueva merced de la mitad de los alumbres el 8 de marzo de 1480. Desconocemos si los Fajardo también consiguieron la confirmación, por cuanto no la hemos hallado, aunque es de suponer que así fuera. De todos estos documentos se sacaron copias en 1510 para ambas casas nobiliarias.

Con estos títulos en la mano, Villena y Fajardo de mutuo acuerdo casi siempre -como más adelante veremos- comenzaron a explotar estas minas mediante contratos de arrendamiento o personalmente a través de sus agentes. Se fueron creando una serie de casas o establecimientos donde residiesen los obreros y sus familiares así como el per. sonal dirigente de las minas. No se sabe cuándo se fundaron estas haciendas pero sí que estaban ya organizadas en 1485 con herramientas, calderas, cubos, picos y demás pertrechos necesarios para la obtención del alumbre (10). Los primeros edificios, como bien afirma Serafín Alonso, se establecieron en la falda noroeste del Cabezo de San Cristóbal de la actual villa de Mazarrón (11). En ellos radicaban las oficinas y tiendas donde se hallaban las herramientas, enseres y domicilios de los agentes de los Fajardo, los arrendadores, fabricantes y obreros que fueron paulatinamente constituyendo una población fija que a fines del

(10) A.D.M.S. Leg. 571.

(11) SERAfin Alonso: Notas para la Historia de Mazarrón, Murcia, 1974, página 131. Agradezco la inmensa amabilidad que ha tenido conmigo el doctor don Juan Torres Fontes al proporcionarme la fotocopia de esta obra y de otras que me han sido de gran utilidad. 
siglo xVI obtuvo de Felipe II el título de villa de Mazarrón (12). Puede pues afirmarse que ya desde 1485 se hallaba creada la fábrica del alumbre situada en un páramo costero cerca de Lorca y poco distante del mar, lugar que como hemos afirmado antes seria llamado mucho más tarde Mazarrón.

En un principio, ambas partes, Villena y Fajardo, entregaron las minas en arriendo a personajes castellanos o genoveses que se compro. metían a elaborar el alumbre que, una vez producido, las dos casas nobiliarias vendían por su cuenta (13). Dos arrendamientos se hicieron bajo estas condiciones pero el tercero ya no se llevó a cabo de esta manera. Efectivamente, a partir del primer cuarto del siglo xvi ambos marqueses proporcionaban el personal necesario que se ocuparía de abrir las minas, conducir las piedras y obtener el alumbre que entregaban por contratos particulares a los arrendadores, a precios determinados, para su venta en el extranjero (14). Es decir, desde ese momento pasaban a ser ellos mismos los que se encargaban de producir el alumbre para después ser vendido por intermediarios genoveses en su mayoria que conocian bien este mercado y que obtenían buena comisión por este negocio.

Villena y Fajardo se pusieron de acuerdo desde un principio en producir cada uno la misma cantidad de alumbre en sus respectivas haciendas con objeto de que no hubiera lugar a desavenencias y litigios entre ambos. A pesar de todo ello las hubo, especialmente cuando entró un tercero en discordia, Cobos, como luego tendremos ocasión de ver. La concordia adoptada entre ambos personajes con vistas a la obtención y venta del alumbre implicaba que cada uno produjese diariamente dos acochas» ordinarias en cada caldera y si alguno dejaba de hacerlas o las

(12) SERAFin Alonso lleva a cabo la transcripción de este documento: op. cit., pág. 131 y págs. 137-151. A.D.M.S. Leg. 570, hay en este legajo y en algunos otros

más diversas copias del título de villa concedido a Mazarrón por Felipe II.
(13) A.D.M.S. Leg. 571 .

(14) Ibidem. 
retardaba podía después, cuando le pareciese, elaborar las que le faltaban (15).

El primer contrato de arrendamiento se firmó el quince de suptiembre de 1485 ante Alfonso del Rincón, escribano de cámara de los Reyes Católicos, entre el marqués de Villena y don Juan Chacón, yerno y sucesor del Adelantado Pedro Fajardo, por una parte, y Alfonso Avellán, vecino de Murcia, Lope de Chinchilla, vecino de Hellín; Fernando de Toledo y el judío Isaquen Abrenalla, vecino de Murcia; de otra parte (16). Los protagonistas del arriendo, como se ve, eran vecinos de Murcia, lugar en el que se hallaba el alumbre y entre ellos aún se encuentra un judío. Todos ellos eran conocidos de Chacón y afectos a su suegro don Pedro Fajardo. El contrato preveía el arrendamiento de las fábricas de Mazarrón por cinco años. Los arrendadores se comprometían a entregar 4.000 quintales de alumbre cada año, a precio cada quintal de $230 \mathrm{mrs}$. y $110 \mathrm{mrs}$. por cada quintal que faltase de los prometidos (17). Si fabricaban mayor cantidad los marqueses la recibirían al mismo precio. Los señores entregaban a sus arrendadores todos los pertrechos necesarios para obtener el alumbre y les autorizaban a construir otra fábrica junto a la existente y además todos los gastos que en este menester hicieren serían pagados por ellos. Los propietarios se reservaban la facultad de rescindir el contrato si en ese tiempo otras personas pagaban más por el arrendamiento de las minas. Asimismo, si los arrendadores quisiesen vender más cantidad de alumbre de la estipulada, quedaban autorizados a hacerlo, pero no podían sacarlo por las costas de Murcia y además habrían de darle a los marqueses la mitad de lo que vendieren bajo esta forma (18).

Asi pues, las minas murcianas comienzan ya a explotarse en la penúltima década del siglo $\mathrm{xv}$, unos años después que las de Tolfa. Delumeau

(15) Ibidem y leg. 570.

(16) Ibidem.

(17) Ibidem.

(18) Ibidem. 
observa que hacia 1486-87 un navio español desembarcó alumbre del Mazarrón en la Esclusa (19). En cualquier caso parece que ya a comienzos del siglo XVI el mineral murciano llegaba a los Países Bajos en can. tidades importantes (20).

El mercado natural del alumbre español, así como el de Roma, fue Flandes en razón de su poderosa industria textil. En concreto fue la ciudad de Anvers la que recibiría mayor cantidad de alumbre hispánico a lo largo del siglo xvi. Después de Flandes fueron Inglaterra y Francia los clientes más importantes del mineral murciano, especialmente la ciudad francesa de Nantes (21). De todas formas será en Flandes donde más se cotice, pero para ello hubo que entrar en competencia con los alumbres italianos, explotados más intensamente, con fábricas muchísimo mayores y con gente más especializada que la del Mazarrón. En esta larga y dura competencia entre unos y otros alumbres acabarían venciendo los italianos a pesar de que en algún momento los murcianos estuvieron a punto de conquistar los mercados, favorecidos además por la Corona española (22).

Es precisamente por estos años cuando entran en escena los primeros genoveses que se van a interesar por este negocio y que al final acabarían dominándolo por completo no sin antes atravesar serias dificultades. Los genoveses habían sido los sucesores de los Médicis en el arriendo de las minas de Tolfa, y ya antes eran por tradición los distribuidores del alumbre en Occidente. Su interés por el alumbre de Mazarrón se inscribe, por tanto, en su deseo de monopolizar el mercado de tan preciado producto. Al mismo tiempo, conocían bien el reino castellano desde hacía varios siglos, eran dueños de importantes negocios en el sur peninsular, especialmente en Sevilla dónde tenían una colonia mercantil

(19) Delumeau: op. cit., pág. 40.

(20) Ibidem.

(21) Delumeau: op. cit., págs. 48-50.

(22) Delumeau: op. cit., págs. 39 y 42 . 
y gozaban de grandes privilegios desde antiguo (23). No eran, por tanto, unos novatos en la peninsula Ibérica, sino que tenían ya una gran experiencia y una red de intereses bien ordenados que les situaba en un primer plano en las actividades mercantiles de la Corona Castellana. De ahí, su interés por controlar el alumbre que muy pronto consiguieron, favorecidos, además, por la propia corona.

Los primeros genoveses que se van a interesar por este negocio fueron los tres hermanos Baltasar, Juan y Domingo Rey, que, el 24 de diciembre de 1486, recibieron en arriendo por seis años las fábricas de Mazarrón, una vez que se rescindió el contrato anterior (24). Al parecer, Luis Rey sc hallaba metido en este asunto del alambre desde unos años antes (25). Según este nuevo contrato, los arrendadores se comprometían a mantener en buen estado todos los utensilios que recibían de la hacienda y a entregar a los marqueses la mitad de todos aquellos que comprasen durante el tiempo del arrendamiento (26).

Por desgracia, apenas sabemos nada de este contrato, ni la cantidad de alumbre que en total se produciria en estos seis años, ni los beneficios quẹ reportaría a ambas partes. ¿Hacia dónde podría haber ido este alumbre? Lo desconocemos, ni siquiera sabemos la cantidad de alumbre que quedó en la península y hacia qué ciudades españolas pudo ir. En cualquier caso, hubo problemas entre los propietarios y arrendadores a! término del contrato. Los primeros enfrentamientos con los genoveses tuvieron lugar en 1483. Ambos marqueses quedaron descontentos de la situación $y$, por consiguiente, les pusieron demanda. Se trataba de que no habían sido entregados una serie de utensilios, que los genoveses exigian el dinero que se habian gastado en otros y que, en concreto Baltasar Rey pedía que le descontaran $70.000 \mathrm{mrs}$. de los treinta días en que

(23) Véase a este respecto Ruth PIKE: Enterprise and Adventure. The Genoese in Seville and the Opning of the New World, Ithaca, New York, 1966.

(24) A.D.M.S. Legs. 570 y 571.

(25) A.D.M.S. Legs. 1334 y 451 . Entre 1480 y 1485 Luis Rey estaba ya mezclado en el asunto del alumbre.

(26) A.D.M.S. Leg. 570 . 
ro pudieron trabajar a causa de la peste (27). Después de una serie de protestas y litigios que ocasionaron una masa enorme de papeles, el 2 de enero de 1494 se llegó a una concordia en la que ambas partes quedaron satisfechas a base de cumplir de pleno acuerdo las exigencias mutuas (28). Al parecer, la producción anual de alumbre que se obtuvo fue de cuatro mil quintales durante los seis años que los hermanos Rey llevaron las fábricas.

Los marqueses consiguieron unos años más tarde, en 1498, que los Reyes Católicos les eximieran a pagar diezmo y almojarifazgo por sus alumbres y almagras y éstas franquezas fueron confirmadas en 1513 al Marqués de Villena por el Rey Católico (29). Se trata de la misma exención de gabelas que se les concedió en Roma a los alumbre pontificios (30). Incluso el mismo tipo de contratos de arriendo de Mazarrón coincide en líneas generales con los que se firman en Tolfa. Hasta tal punto ello es cierto, que nos atreveríamos a afirmar que parece que fueron copiados de los de Roma por los genoveses, a pesar de que la hacienda de Tolfa era más compleja que la de Mazarrón, puesto que se trataba de la mayor empresa minera de Europa en el siglo Xvi en frase de Delumeau (31).

Entre 1494 y 1525 la documentación estudiada silencia la situación de los alumbres murcianos, no nos indican las cantidades que se produ-

(27) A.D.M.S. Leg. 570.

(28) Los jueces elegidos para este menester obligaron a los genoveses a entregar la mitad de las herramientas y carpinteria al Procurador del Adelantado. En cuanto a la caldera, que según los genoveses la habían hecho despućs del arrendamiento, habían de dar la mitad al Adelantado sin hacer de ello descuento. Se les ordenó también que pusieran las puertas que faltan en la fortaleza y que dentro de cuatro meses repararan la cámara que quemaron y que limpien las pedreras. Por otra parte se probó que los genoveses gastaron $1.500 \mathrm{mrs}$. en la linterna que hicieron en el pozo de las Heras, en la pared de las calderas 6.130 maravedis, en el pozo $6.500 \mathrm{mrs}$., en el gallinero $900 \mathrm{mrs}$, en los terrados que están sobre las calderas $2.000 \mathrm{mrs}$., y en la herrería $450 \mathrm{mrs}$. A.D.M.S. Leg. 570 .

(29) A.D.M.S. Leg. 571. PILAR LAON TELLo: Inventario..., Doc. n. 1.701, 1498, mayo, 19. Toledo. Copia autorizada de 1509.

(30) Delumeau: op. cit., pág. 79.

(31) Delumenu: op. cit., pág. 77 . 
cian ni los precios a los que se vendía. Todo ello nos conduce, sin lugar a dudas, a dar de éste asunto una visión incompleta y fragmentaria que ni siquiera la documentación del marquesado de Villena nos ayuda a superar. Ignoramos no sólo la cotización del mineral, sino también la producción anual del mismo, los beneficios que reportaba a sus dueños, los intermediarios, el número de obreros y los salarios que percibian sus familias, etc. D. Ramón Carande, a este respecto, observa una baja de precios en el mercado flamenco al entrar en competencia los alumbres murcianos con los españoles (32). Así, entre 1465 y 1513 -afirma el gran historiador - la renta de los alumbres pontificios bajó considerablemente de 100.000 a 15.000 ducados (33). Las investigaciones de Delumeau, basadas en la lectura del trabajo mecanografiado de Felipe Ruiz Martín nos ayudan un tanto (34). Según Delumeau en 1513 el Papa León X trató de que los genoveses, que tenian en ese momento el arriendo de sus minas, intentasen cerrar todos los alumbres españoles para evitar la competencia (35). Se trata, por tanto, de una prueba clara de que los alumbres murcianos estaban haciendo bastante daño en el mercado a los romanos, pues de otra manera, el papado ni siquiera se hubiese preocupado de ello. Desde comienzos del siglo xvi Agostino Chigi llevaba en arriendo las minas papales enviando a Flandes la cantidad anual de 46.317 cántaras de alumbre, obteniendo de todo ello tan impresionantes beneficios que se hizo construir, entre otras muchas cosas, un hermosisimo palacio en Roma (36). Pues bien, el Papa encargó a Chigi y a Bellanti que consiguieran un acuerdo de los productores españoles del alumbre con vistas a reducir su impontancia en Flandes (37). Ambos genoveses llegaron a ofrecer a los españoles la compra anual de 18.000 cántaras de mineral murciano. con la condición de que éstos últimos no fabricasen más cantidad de los 18.000 estipulados (38). Los marqueses

(32) Ramón Carande: op. cit., pág. 353.

(33) Ibidem, pág. 353.

(34) Delumeau: op. cit., págs. 40 y ss.

(35) Ibidem, pág. 40.

(36) Ibidem, págs. 97 y 104.

(37) Ibidem, pág. 40.

(38) Ibidem. 
de Vélez y Villena, asi como el licenciado Vargas que explotaba las minas descubiertas en 1509 en Rodalquilar (Almería), pusieron como condición, para concluir este acuerdo, que se llegase a una verdadera igualdad de producción entre sus alumbres y los de Tolfa, ya que éstos producían más de esa cantidad (39). Sin embargo, no hubo acuerdo, y ello pese a que hacia 1520 la unión entre los distintos productores de alumbre era inevitable según la conclusión a que llega en 1522 Chinchilla, agente del Marquésde los Vélez en los Países Bajos, en una carta enviada a su amo el 25 de diciembre de 1522 (40). La muerte de Chigi en 1520, provocó una crisis en la explotación de Tolfa que favoreció, según Delumeau, la entrada en los Países Bajos del mineral castellano (41). De todas formas, desconocemos la incidencia real que pudo causar este hecho, pues, es únicamente a partir de 1525, cuando volvemos a disponer de noticias, ahora mucho más ricas, sobre el asunto que nos ocupa.

\section{EL APOGEO}

Hasta 1525 el negocio del alumbre marchaba regularmente bien, con los problemas normales que un asunto de éste tipo podía plantear a sus propietarios inmersos, además, en otros asuntos relacionados con sus estados y con la política del reino. Preocupaciones las había habido, fricclones entre arrendadores y dueños también, pero no habían sido excesivamente graves, ni habian suscitado ningún pleito enojoso.

Pero, fue en ese mismo año de 1525, que se produjo el descubrimien. to de varias minas de alumbres en el término de Lorca, cuando comenzaron los problemas serios. Tras ese nuevo hallazgo Vélez y Villena, casi de inmediato, acudieron a Carlos $\mathrm{V}$ para que éste les confirmara en la posesión de esos alumbres, de acuerdo con el documento original de Enrique IV, en el que éste monarca les había concedido a perpetuidad

(39) Ibidem.

(40) Ibidem.

(41) Ibidem. 
todos los alumbres descubiertos y por descubrir del reino murciano. Sin embargo, intereses más poderosos cerca del nuevo monarca entraron єn juego. El Comendador Mayor de Castilla, Francisco de los Cobos, secretario y persona de confianza de Carlos $\mathrm{V}$, solicitó de éste la concesión de las nuevas minas de Lorca (42). Cobos, hombre astuto y de gran inteligencia, debía de conocer las provechosas ganancias que el alumbre proporcionaba a sus dueños y a la Real Hacienda. La rapidez con que actuó y consiguió del monarca la concesión de estas minas, cogió de sorpresa a Villena y Fajardo. Protestas de los marqueses, pleitos, enemistades y litigios de nada sirvieron $y$, así, Cobos obtuvo del Emperador en 1525, 1527 y 1534 tres reales cédulas por las que recibía las minas recién descubiertas a siete leguas de Lorca y las que se descubrieron a seis leguas de Cartagena (43). Cobos quedaba obligado a pagar a la Real Hacienda la décima parte del alumbre furidido $y$ afinado en pasta $y$, asimismo, se comprometía a la apertura y explotación de las minas en el espacio de tres años a partir de 1525 (44). Se abrieron cuatro pozos por Juan de Alcázar, Alcalde Mayor de los alumbres del marqués de los Vélez, autorizado por Cobos para esta empresa y a la que se prestó de buen grado con objeto de beneficiar a don Pedro Fajardo, sucesor de don Juan Chacón (45).

De todas formas y a pesar del éxito obtenido al conseguir la cesión de este alumbre, Cobos comprendió que era imposible explotar las minas sin el concurso del marqués de Vélez, porque éste era veterano en el negocio, conocía bien el mercado y a los mercaderes que se encargaban del suministro del mineral. Había, por tanto, que llegar a un acuerdo, aunque fuese al precio de una renuncia. Y, asi, en 1528 Francisco de los Cobos y Pedro Fajardo se concertaron en dividir por la mitad las

(42) A.D.M.S. Legs. 33, 570 y 571.

(43) Ibidem. La primera concesión fue firmada por el monarca en Toledo el 30 de junio de 1525; la segunda se expidió en Burgos el 13 de diciembre de 1527 y. finalmente, la última se dio en Madrid el 2 de diciembre de 1534. Pilar LEón: op. cit., Doc. n.* 1.710. Copia de 1539 y Doc. n. 1.713 . Copia de 1539.

(44) A.D.M.S. Leg. 571.

(45) Ibidem. 
minas de Cartagena y Lorca, con la condición de que el segundo dejase al primero la mitad de los alumbres que se produjesen deduciendo los gastos de su elaboración (46). Aparentemente el conflicto se solucionaba con este acuerdo pero, no tardarían en surgir nuevos problemas. Cobos habia entregado a los marqueses solamente la mitad de los alumbres que había recibido para que ellos la explotasen, pero seguía conservando la otra mitad. El plan de Fajardo - seguido por Villena- consistía en apoderarse de todos los alumbres del secretario del monarca, precisamente con este objetivo habia accedido a firmar el acuerdo de 1528, como un primer paso para conseguir su meta. Esta llegaría, pero muy a largo plazo, y por cierto, bastante hipotecada, como veremos.

Por de pronto, el flamante Cobos se dispuso explotar la parte de los alumbres que seguía manteniendo después de la concordia con Vélez. Decidió para ello utilizar como mano de obra a la población musulmana que allí permanecía (47). Pocos años más tarde el secretario del Emperador se vio obligado a aumentar su personal obrero, echando mano de cristianos viejos que le parecían trabajadores más seguros que los moros. Pero no era fácil atraer pobladores para sacar el alumbre de las minas, pues se trataba de un trabajo pesado y con muchos inconvenientes. Había por tanto que hacer previamente una serie de concesiones. Cobos obtuvo del Emperador el 8 de enero de 1535 que a sus futuros pobladores se les otorgasen las mismas franquicias que a los vecinos de Cartagena, que no pagasen alcabalas ni almojarifazgos, ni ellos ni sus alumbres murcianos de Mazarrón, ni los de Rodalquilar en el Obispado de Almería (48).

Sin embargo, el Comendador Mayor de León y futuro Marqués de Camarasa no se hallaba satisfecho de cómo marchaba la producción de sus alumbres, que no le eran, al parecer, muy rentables. Decidió, por

(46) Ibidem y leg. 452.

(47) Ibidem. Especialmente para trabajar las minas del Pago del Cabezón Roche y el de la Fuente de Aldeán.

(48) Ibidem. 
tanto, acudir a otro procedimiento para obtener más beneficios y precisamente con ello, iba a complicar aún más la confusa situación en que se encontraba el negocio del alumbre. Efectivamente, el 3 de octubre re 1536 formó una compañía con Hernando de Baeza, vecino de Sevilla, durante diez años, para que éste explotase y vendiese el alumbre con la condición de que si en ese tiempo alguien pretendía tener mejor derecho que Cobos a los alumbres, nombrasen respectivamente cada uno de ellos dos letrados para que ellos fuesen los encargados de resolver el pleito (49). Los beneficios se repartirían por mitad entre ambos asociados. Esta última cláusula mencionada ponía al descubierto el verdadero juego de Cobos que, al no tenerlas todas consigo sobre su derecho al alumbre, trataba de salvaguardarse y comprometer en su delicada situación a otra persona con posibilidades económicas que pudiese ayudarle. Juego astuto y peligroso que no iba a dar los resultados esperados por el intrigante secretario, antes bien, iba a provocar la enemistad de los interesados en el negocio y un largo y enojoso pleito que a nada condujo.

Apenas la compañía empieza a dar sus frutos, cuando sucedió lo que Cobos temía. El marqués de Villena, don Diego López Pacheco, se opuso a este concierto esgrimiendo el documento de Enrique IV y su confirmación por los Reyes Católicos en 1480 (50). Villena, junto con Vélez, acordaron el 27 de julio de 1537 ofrecer a Cobos una serie de compensaciones si renunciaba a las tres mercedes regias que había obtenido y si les entregaba sus minas libres de la compañía de Hermando de Baeza (51). Ambos marqueses se comprometían a entregar a Cobos por su renuncia 2.500 ducados de oro, $937.500 \mathrm{mrs}$. de renta anual que ambos personajes pagarian por mitad, además del precio de los edificios obras, y los gastos en descubrir y limpiar las canteras, mineral, lejías, bestias y pertrechos que hubiese en toda la fábrica (52). Cobos, en un principio dudó de la

(49) Ibidem. Pilar LeÓN: op. cit., Doc. n.॰ 1.715, 1536, octubre, 3.

(50) ILidem.

(51) Ibidem.

(52) Ibidem. 
conveniencia de aceptar esta jugosa oferta, pero muy pronto se convenció de que le era mucho mejor ceder y deshacerse de un negocio que sólo problemas le había acarreado. Y asi decidió en 1539 vender una gran parte de sus alumbres en favor de los otros dos protagonistas (53). Dos años más tarde, el 31 de diciembre de 1541 y después de algunas peripecias, se llegó al acuerdo definitivo. Cobos renunciaba en favor del marqués de Vélez a los alumbres que tenía en Cartagena y Lorca, libre de la compañía de Baeza (54). A cambio de ello recibía de don Pedro Fajardo un juro de $140.000 \mathrm{mrs}$ de renta, las salinas de Pinilla estimadas en 273.570 mrs. y quedaba obligado el mayorazgo de Vélez, a satisfacer los 55.180 mrs. que faltaban para los 468.750 mrs., que era la parte que a él correspondia de los 2.500 ducados que, junto con Villena, se habia comprometido a pagar en el acuerdo 1537 (55). Al ser los juros ofrecidos propios del mayorazgo, el marqués de Vélez pedía a Cobos que pudiese recuperarlos dentro de ocho años.

El marqués de Villena, por su parte, entregó a Cobos un juro viejo perpetuo de 150.000 mrs., situados en las rentas de Baza y su tierra y las salinas de Pinilla que rentaban 300.000 mrs. anuales, más 1.000 mrs. que se pagan de ellas cada año. Pacheco se obligó a comprar el resto de la renta que eran $28.750 \mathrm{mrs}$, a razón de $30.000 \mathrm{mrs}$. el millar, pero con la condición de poder comprarle estos juros (56).

Cobos llevó a cabo estas ventas en tres fechas sucesivas, el 27 de julio de 1537 en Valladolid, el 18 de noviembre de 1538 en Toledo $y$, finalmente, en 1541. Carlos V confirmó la venta por un privilegio firmado en Toledo el 7 de marzo de 1539 (57). Al parecer, según todos los indicios, fueron los genoveses los que ayudaron a Villena y Vélez a pagar al marqués de

(53) Ibidem.

(54) Ibidem y leg. 33.

(55) Ibidem.

(56) Ibidem y leg. 5.101 .

(57) Ibidem. El marqués procuró siempre no enemistarse con Cobos porque sabía que era el favorito de Carlos V. A pesar de todo, el marqués se queja mucho en sus cartas de la actitud del monarca y de la ambición de Cobos. 
Camarasa el precio de sus minas adelantando importantes cantidades de dinero como arrendadores de las haciendas murcianas (58). D. Pedro Fajardo acudió a Esteban Doria, Pantaleón de Negrón y Jerónimo Ita. liano, quienes, en nombre de sus respectivas compañías, llevaron a cabo el pago de su deuda y todo lo que montaron las calderas y utensilios de la fábrica de Cobos (59).

Pero esta renuncia no fue completa ni tan fácil como hasta ahora la venimos presentando. Dos personajes se sintieron perjudicados con la venta de Cobos, Hernando de Baeza y el heredero de Vélez, don Luis Fajardo, marqués de Molina. Al primero apenas si se le había tenido en cuenta siendo el primer lesionado, puesto que había formado una compañia en Cobos y con la venta se le trastocaban todos sus planes, don Luis Fajardo, soldado impetuoso e irreflexivo pero consciente siempre de su situación, protestó de este hecho el 21 de mayo de 1541 porque la venta hipotecaba el mayorazgo y que al ser heredero de éste, le debían haber pedido su consentimiento y aprobación. Al final no tuvo más remedio que aceptar los hechos consumados y se limitó a escribir a su padre una carta durísima y amarga que ponía de relieve las malas relaciones que existian entre ambos desde hacía cierto tiempo (60). Baeza, por su parte, puso pleito a Cobos, aún sabiendo que llevaba todas las de perder por tratarse de un personaje tan influyente cerca del Emperador. Después de algunos años de forcejeo, Hernando de Baeza se vio obligado a entregar al Comendador y a los marqueses la mitad de la fabricación y pertrechos de los alumbres de Cartagena y Lorca y a dar cuenta de lo que habian rentado. Se les condenó además a que dentro de veinte dias se presentase en la Hacienda y entregase a Cobos la cuenta de los alumbres que había gastado bajo la pena, si no lo hiciese, de m:l

(58) Ibídem. Gaspar Rótulo, arrendador de las minas de Vélez por estos años, confiesa en una de sus cartas que el marqués no disponía de dinero para comprar las minas de Cobos. Sólo en el momento en que dispuso de las sumas entregadas por los genoveses fue cuando llevó a cabo esta operación.

(59) Ibidem.

(60) A.D.M.S. Leg. 570. 
ducados (61). Bajo estas perspectivas Baeza cedió y de esta forma todo el alumbre de don Francisco de los Cobos pasó a poder de los marqueses de Villena y Vélez.

De todas maneras el problema de Cobos no terminó por completo con estas capitulaciones. Muerto don Pedro Fajardo, su sucesor don Luis puso una demanda a don Diego de Cobos, marqués de Camarasa, hijo de don Francisco, y a su madre doña María de Mendoza por no haberle entregado todos los alumbres que le pertenecian en virtud de los acuerdos anteriores (62). El litigio no finalizó hasta el año 1581 en que la chancillería de Granada falló a favor del marqués de Vélez, restituyéndole todos los alumbres del Obispado de Cartagena y del reino de Murcia con todos los frutos y rentas que hubiesen producido (63).

Al mismo tiempo que se producían estos hechos, los protagonistas del alumbre tuvieron que hacer frente a otro delicado asunto. Efectivamente, la ciudad de Lorca puso un pleito al marqués de Vélez porque sus vasallos de Mazarrón utilizaban madera y leña de su término para la elaboración del alumbre sin ser vecinos de la ciudad (64). Los marqueses respondieron a este requerimiento argumentando que ellos disponian de un privilegio de Alfonso $\mathrm{X}$, conquistador de Murcia, por el cual se ordenaba que Murcia, Lorca, Librilla, Alhama, etc., tuviesen comunidad de términos los unos y los otros y que, por lo tanto, gozaban de la regalia de cortar leña en término de Lorca (65). Al mismo tiempo, Vélez manifestó que él era Alcaide de Lorca, Adelantado y Capitán Gene. ral perpetuo del reino de Murcia, y que de esta manera era vecino de Lorca (66). Además los alumbres no podían fabricarse sin madera y al

(61) Ibidem.

(62) A.D.M.S. Leg. 571.

(63) Ibidem.

(64) PIlar León: op. cit., Doc. n. 1.718, 1540, julio, 22. Original. A.D.M.S. Legajos 571, 1.657 y 1.298. Don Pedro Fajardo en una de sus cartas manifiesta que la gente de Lorca «se desvela en maldades y en darme todos los enojos que puede".

(65) A.D.M.S. Legs. 570 y 1.163.

(66) Ibidem. 
cortar esa leña se aclaraban los montes y se evitaban muchos daños que los piratas musulmanes podían hacer en ese término como lo habian hecho en otros. Concluian afirmando que los alumbres reportaban grandes beneficios a Lorca. Al mismo tiempo Villena y Vélez hicieron saber a la chancillería de Granada que más de quinientos vecinos de Lorca vivían de todo aquello que ambos gastaban y costeaban en la Hacienda de Mazarrón, puesto que eran ellos los que la abastecían y, por tanto, a esa ciudad le venía más provecho que daño (67). El argumento decisivo que se utilizó para ganar el pleito contra Lorca fue el hecho de que la fábrica del alumbre aservia a Dios y a su Majestad por los diezmos, alcavala e tercias en mas de un quento de manera que aunque a los particulares les viniese algún daño no podían protestar de cllo «porque la utilidad pública se prefería a la privada» (68). Ante tales razonamientos que claramente comprometían a la Corona, el pleito se falló a favor de los marqueses el 9 de agosto de 1540.

Hasta ahora nos hemos detenido en dos hechos de gran importancia que era necesario conocer para completar el panorama político y las ambiciones de poder que suscitó la cuestión del alumbre. No hemos narrado aún los nuevos contratos que se firmaron en estos años en los que se inicia el apogeo de las fábricas. Si desconocemos la rentabilidad, precios, producción, etc., que produjo a Cobos sus minas, pese a que lo hemos intentado, en cambio, poseemos numerosas noticias de las de Mazarrón.

El 8 de octubre de 1532 el marqués de Vélez entregó en arriendo a Gaspar Rótulo Milanés, vecino de Almagro, todos los alumbres de Mazarrón por nueve años, a partir de enero de 1553, a precio de $630 \mathrm{mrs}$. cada quintal (69). Rótulo obtuvo en 1537 la cantidad de 13.802 quintales y veintiséis libras de alumbre que vendió en el mercado de Flandes (70).

(67) Ibidem.

(68) Ibidem.

(69) A.D.M.S. Legs. 570 y 571.

(70) Ibidem. En 1537 Gaspar Rótulo pagaba cada quintal a razón de $550 \mathrm{mrs}$. 
Rótulo, que unos años antes habia hecho un buen matrimonio, cerró las minas de Rodalquilar que desde hacía cierto tiempo llevaba en arriendo (71). En el contrato que hizo con don Pedro Fajardo se estipulaba que Rótulo produjese anualmente la cantidad de 14.000 quintales, pero al parecer no llegó a cumplir esa cifra, pese a que se aproximó mucho a ella.

De pronto el contrato con Gaspar Rótulo fue clausurado cuatro años antes de expirar, y, en su lugar Vélez arrendó sus fábricas a tres compañias genovesas, representadas por Esteban Doria, Pantaleón de Negro y Jerónimo Italiano (72). La razón de este brusco cambio de actitud hay que buscarla en los intereses de Carlos V. Efectivamente, el monarca aconsejó a los marqueses que entregasen el alumbre a los italianos, expertos en el negocio, a los que debía dinero y con los que había concertado algunos acuerdos (73). Al parecer, el monarca que recibía más de un millón de maravedis por los impuestos sobre el alumbre, pensó que éstos aumentarían al arrendárselo a los genoveses. Los italianos se comprometieron a producir alumbre durante los quince años que duraria el tiempo del contrato estipulado, pagando a los marqueses la cantidad de 12.500 .000 mrs. anuales por mayo y octubre en las ferias de Medina del Campo y Villalón (74). Los marqueses se repartirían esta cantidad por mitad. A los genoveses se les entregaron todos los utensilios y per. trechos que había en Mazarrón, tendrían que repararlos a su costa y los dejarian al cabo de los quince años tal como los recibian ahora. En el momento de entregar las fábricas Villena y Fajardo, para evitar futuros problemas que en otras ocasiones habian surgido, hicieron tasar todo lo que poseían en ellas por dos veedores nombrados por cada uno. Al llevarse a cabo la firma de este contrato, el monarca, agradecido a los

(71) Casó en 1529 con María Carrillo Osorio, hija de Hernán Carrillo de Toledo y de doña Juana Osorio. Indice de la Colección Salazar y Castro, tomo XXXII números 50.550 y 50.551, págs. 17 y 18.

(72) A.D.M.S. Legs. 1.126, 570 y 571 .

(73) Ibídem. PIlar LeON: op. cit., n. 1.719, 1551, enero, 29.

(74) Sobre los Negro, Delumeau: op. cit., págs. 220 y 221. A.D.M.S. Leg. 570. 
marqueses prometió enviar mil fanegas de pan y cebada a la fábrica del alumbre (75).

He aquí el contrato más largo de todos los que hasta este momento se habian firmado, se hizo asi por la intervención de la corona, la competencia profesional de los arrendadores y las sumas de dinero que éstos últimos aportaban a las arcas de los propietarios. No había más remedio que llegar a este acuerdo, por ello se había previsto un plazo largo, ya que el negocio se habia complejizado y los genoveses eran los únicos que podían dinamizarlo y cotizar bien en el mercado los alumbres murcianos. Fue, pues, la necesidad y la cordura demostradas por los dueños las que hicieron posible que a partir de estos años el alumbre español batallase de manera muy dura contra el de Tolfa en el mercado flamenco. Desde los años cuarenta de la centuria decimosexta podemos pues afirmar que comienza el apogeo del alumbre de Murcia.

Las compañias genovesas se comprometían a no labrar anualmente más de 40.000 quintales que montarian al término del arrendamiento la respetable cantidad de $600.000 \mathrm{mrs}$., y si al final sobraban alumbres, los marqueses los recibirían al precio que en ese momento costasen (76). Quedaban obligados a descubrir anualmente dos pedreras de alumbre, una para cada señor, $y$, asimismo labrarian diariamente dos cochas en cada caldera. Los marqueses nombrarían dos veedores para inspeccionar la buena marcha del negocio, cada uno de los cuales cobraría 50.000 maravedies, cantidad que pagarían los genoveses (77). Finalmente, si ambos propietarios tuviesen necesidad de recibir dinero por adelantado en las ferias, en Flandes o en Italia, los genoveses deberían satisfacerlo.

Para vigilar sus negocios en Flandes y sobre todo para evitar que las compañías genovesas les burlasen, ambos marqueses nombraron sus factores en Flandes. La copiosa correspondencia que mantuvo el primer

(75) A.D.M.S. Leg. 570.

(76) Ibidem.

(77) Ibidem. 
marqués don Pedro Fajardo y que se conserva casi en su totalidad nos descubre algunas incidencias del mercado flamenco. D. Pedro era muy dado a escribir y muy sincero en sus cartas, en las que vierte juicius $y$ opiniones de muchas personas. Especialmente interesante es la consideración que tenía de los genoveses, a los que llama mentirosos que "tiran la piedra y esconden la mano", y pide a Dios que "cuando le lleve de este mundo vaya al Paraiso, pero no en compañía de los genoveses", ni de cualquier otro género de mercaderes (78). El marqués afirma que Flandes no puede vivir sin sus alumbres $y$, sin embargo, tanto en el mercado flamenco como en el de Inglaterra se cotizaban más los alumbres italianos que los de Mazarrón, salvo los alumbres blancos de Cartagena (79).

En la década de 1530-1540 Villena tuvo problemas con Vélez a propósito de las minas que progresivamente se iban abriendo. Sobre este conflicto no estamos muy bien informados, en cuanto a los motivos de la discordia. Ciertamente en un negocio tan conflictivo como en el del alumbre era lógico que estallasen fricciones, dado que la propiedad la compartían dos personas, y ello a pesar de que desde un principio ambos marqueses se habían fijado con toda minuciosidad los límites respectivos de ambos. De todas formas, los celos, las discordias entre el personal dirigente de una y otra fábrica y sobre todo el hecho cierto del descubrimiento de pequeñas minas de alumbre, contribuyeron a que durante algunos años las relaciones entre Villena y Vélez no fuesen tan cordiales como lo habían sido hasta ese momento. A ello se añade el hecho cierto de que Villena producía más cantidad de alumbre en su hacienda que Vélez, lo que molestaba lógicamente a este último, pues violaba la concordia inicial que entre ambos propietarios se habia llevado para que uno no fabricase más mineral que otro (80). Delumeau ha compro-

(78) A.D.M.S. Legs. 1.298 y 1.657. A juzgar por esta correspondencia el marqués de Vélez tuvo muy buenos administradores de sus fábricas. A.D.M.S. Leg. 5.101.
(79) Ibídem.

(80) A.D.M.S. Leg. 570. 
bado que el marqués de Villena producía y vendía en Flandes más cantidad de alumbre no sólo en estos años sino también en los siguientes (81).

Dentro de esta animadversión entre ambos se halla el hecho de que en 1537 el administrador del marqués de Vélez, Luis de Bocanegra, exige a Francisco de Narváez, alcalde de Villena, y a Lope de Acuña, su gobernador, que le entreguen las pedreras descubiertas por Bartolomé Bezón por encontrarse en territorio de don Pedro Fajardo (82). La negativa fue fulminante lo que muestra que los términos entre una y otra hacienda no se hallaban absolutamente fijados. Vélez ordena que se limpien las pedreras. La situación se deteriora hasta que estalla el conflicto el 24 de abril de 1542 (83). Pleito e información de testigos en Lorca. Varios informes, preguntas, respuestas inconexas al gusto de los que son criados de uno y otro señor. Dos años más tarde nuevo conflicto por las pedreras entre Riquelme de Arroniz, por parte de Vélez, y Arias de Silva, por la de Villena (84). En este último conflicto es el marqués de Villena quien exige la devolución de la pedrera de Agustín, porque se hallaba en los límites de su hacienda (85). Sin embargo, la reconciliación llegó demasiado pronto y de forma inesperada. Efectivamente, ambos marqueses olvidan sus rencillas ante un nuevo y jugoso contrato de arrendamiento con la compañía más acaudalada de Castilla, la de Ansaldo de Grimaldi, que se firmaría el 14 de septiembre de 1542.

En un principio, la compañía genovesa intentó arrendar el alumbre por treinta años, pero sus propietarios se negaron a ello con el pretexto de que se trataba de muchos años y que durante ese tiempo no podrían controlar sus haciendas (86). Querian tener las manos libres para llevar

(81) Delumeau: op. cit., pág. 39.

(82) A.D.M.S. Leg. 570.

(83) Ibídem.

(84) Ibidem.

(85) PILAR León: op. cit., Doc. n. 1.716. Copia simple. A.D.M.S. Legs. 570 y 571.

(86) PILAR LeÓN: op cit. Doc. n..' 1.719, 1551, enero, 29. A.D.M.S. Legs. 1.307, 570, 571, 1.126 y 5.101. En 1539 Esteban Salvago y Francisco de Lomelín, en nombre de Ansaldo de Grimaldi, habían entrado en tratos con el marqués de Villena, ofreciéndole las mismas condiciones que unos años después ofrecieron a Vélez. 
a cabo en el futuro otros arrendamientos, que les proporcionaran superiores ganancias, o al menos, controlar la compañia de Grimaldi. Los marqueses pensaban que si arrendaban las minas por treinta años el precio impuesto a los genoveses sería el mismo durante todo ese tiempo y en cambio la cotización del alumbre en ese tan largo período podía subir y perder, por tanto, futuros beneficios. Así, pues, se les arrendó las haciendas a los genoveses por nueve años, por precio cada año de ocho millones de maravedis y con la condición de que fabricaran anualmente 20.000 quintales de alumbre (87). Previamente se anuló el contrato con la compañia de Doria fijado en quince años, y, que de esta manera, sólo había durado seis (88). Estas anulaciones de contratos estuvieron a la orden del día en el negocio del alumbre, pues los marqueses buscaban siempre mayores beneficios y apenas si tenían en cuenta a sus arrenda. dores, siempre con el concurso y apoyo de la corona. Los Grimaldi arrendadores del alumbre murciano eran los mismos que llevaban la explotación de las minas pontificias de Roma desde 1541 (89). Se trataba de tres hermanos, Ansaldo, Lucca y Giovanni Batista Grimaldi. Esta familia llevó a cabo, unos años más tarde, un contrato con Carlos $V$, reservándose el monopolio de importación del alumbre en los Países Bajos (90). Ellos se convinieron en hacer llegar cada año 4.666 cargas de España y 3.333 cargas solamente de Tolfa.

El único contrato de arrendamiento que fue cumplido escrupulosamente fue este último firmado por Ansaldo de Grimaldi, pues expiró el 29 de enero de 1551, es decir, justo los nueve años estipulados (91). Los genoveses pagaron cuatro cuentos de mrs. en una feria y otros cuatro

(87) A.D.M.S. Legs. 570 y 5.101. 20.000 quintales por cada fábrica, en total 40.000 quintales. En 1541 los marqueses habian obtenido la cantidad de 88.000 du. cados como beneficios de sus alumbres.

(88) Ibidem.

(89) Delumenu: op. cit., págs. 96 y 99.

(90) Delumeau: op. cit., pág. 41.

(91) A.D.M.S. Legs. 570 y 1.163. En 1544 Micer Jerónimo Vivaldi se queja de que no puede entenderse con Villena, y manifiesta que los alumbres que llegan a Flandes son muchos, que no tienen ninguna reputación y que, por tanto, las fábricas deben reducir su producción. 
en la otra. Los arrendadores en nombre de los herederos de Grimaldi fueron fray Vincentio Lunel y Micer Jerónimo Vivaldo (92). Vélez tenía necesidad de dinero y exigió a los genoveses un préstamo que oscilaría entre cuatro y ocho mil ducados, a cambio del cual el entregaria los alumbres que necesitasen según la cuantía del préstamo (93). Los genoveses exigieron a los marqueses que cerraran la fábrica de Cartagena y en compensación de sus posibles pérdidas ellos les pagarian como renta mil ducados. Los arrendadores no pagarian nada el año en que se declarara peste o hubiese alguna entrada de moros $u$ otro cualquier caso for. tuito (94). No pagarían alcabalas ni almojarifazgos y si algún pleito se suscitase en esos años los marqueses y sus veedores se harian cargo de él. Villena y Vélez entregarían a sus arrendadores todos los edificios y pertrechos de sus haciendas y aportarían 15.000 ducados en lejias, calderas, herramientas, mulas, carros y sus aparejos. La limpieza de las minas la habían de llevar a cabo los genoveses corriendo los gastos a costa de los marqueses. Finalmente, si el alumbre subía de cotización, $\in$ l marqués de Vélez entraba en las ganancias y también en las pérdidas, tanto en los veinte mil quintales suyos como en los del marqués de Villena (95).

Asi pues, los Grimaldi conseguian de esta forma el monopolio de la importación de alumbre en Anvers, y parece que fueron mejores clientes de Villena que de Vélez (96). El papado no pudo, por tanto, mantener el monopolio del alumbre romano en los Países Bajos y menos aún en España. Pero, aún así, la producción de alumbre castellano no igualó

(92) Los genoveses exigieron también al marqués de Vélez que el contrato fuese ratificado por su hijo el marqués de Molina. Vélez prometió que cerraría las fábricas de Cartagena a cambio de que le entregaran 40.000 ducados. El marqués, además, quiso que se tasaran las aherası y que dentro de dos meses los genoveses le pagasen la suma que montaran esas aheras:; él les entregará todos los alumbres que se hubiesen fabricado al tiempo de la celebración del contrato. A.D.M.S. Leg. 570 .

(93) A.D.M.S. Leg. 570.

(94) Ibidem.

(95) Ibidem.

(96) Delumeav: op. cit., pág. 39. 
nunca a la de la empresa de Tolfa en el mismo periodo (97). En el momento de máxima producción hacia 1562, las fábricas españolas daban aproximadamente 26.000 quintales por año, de esta cantidad 12.000 quintales procedían de la explotación de Villena, 8.000 de la de Vélez y 6.000 de la de Cartagena, mientras que la explotación de Tolfa en ese año era de 36.000 cántaras de alumbre (98).

Felipe Ruiz Martin se ha preguntado porqué los Grimaldi que eran también arrendadores de Tolfa concluyeron con Carlos $\mathrm{V}$ el acuerdo ya mencionado. La explicación de ello se halla, según este historiador, en que hallándose próxima la guerra con Francia, cuyo escenario iba a ser precisamente Flandes, los Grimaldi debían aportar el dinero a los comisarios de guerra y como la paga de estas sumas de los Grimaldi debía efectuarse en Sevilla y aún no se podía sacar el numerario de la penin. sula los genoveses tendrian que invertirlo en compras de productos españoles exportables, el único que podría merecerles la pena era el alumbre y en él lo hicieron (99). Delumeau ha aportado una segunda explicación de ello. Según el historiador francés, los Grimaldi no se hallaban hacia 1551 interesados en la empresa de Tolfa, ya que su contrato finalizaba dos años más tarde y el Papa había concluido un acuerdo de arriendo de sus minas en 1549 con Agostino y Bendinello Sauli, que iba a durar doce años desde 1553 a 1561 (100).

A pesar de todo, los alumbres hispánicos, que conocieron su apogeo al mismo tiempo que los de Tolfa, no lograron vencer a éstos en el mercado durante estos años porque la gobernadora de los Países Bajos concertó un acuerdo con los Sauli que llevaban ya las minas del Papa a base de introducir en estos mercados 8.000 cargas anuales de alumbre (101).

(97) Ibidem.

(98) Ibidem.

(99) Delumeau: op. cit., pág. 42.

(100) Ibidem.

(101) Ibidem. 
Nada sabemos de los contratos posteriores a 1551 salvo noticias fragmentarias que nos proporciona el archivo del marqués de Villena. Así el 14 de enero de 1555 la princesa doña Juana concedió licencia a don Diego López Pacheco, marqués de Villena, para llevar a Francia treinta quintales de alumbres en el plazo de un año (102). Unos años más tarde, en 1561, Villena ordenó a su contador Mayor Perales, que el dinero cobrado de la venta de los alumbres a Alonso de la Torre, se entregue a su hermana doña Luisa Pacheco en pago de su legítima (103). En $1565 \mathrm{Fe}$ lipe II ordenó que se incorporaran a la corona todos los alumbres que pertenecientes a particulares, estuviesen sin explorar, dando a cada uno la indemnización correspondiente (104).

En 1565 se firmó un nuevo contrato con otra compañía de genoveses formada por Negrón de Negro, Agustín Sauli y Alberto Penello (105). Los apellidos son suficientemente significativos $y$ nos ahorran, por tanto, todo comentario. El contrato caducó hacia 1574(106). Negrón de Negro consiguió de esta manera el monopolio del alumbre castellano. Disponia de varios agentes en Anvers, entre los cuales el más importante cra Giovanni Batista Spinola, que se asoció con mercaderes alemanes como los Schetz 107). Negro formó un acuerdo con el gobernador de los Países Bajos por el cual importaría 4.000 cargas anuales de alumbre durante nueve años (108). Es, quizá, éste el momento de mayor esplendor de las minas murcianas, cuando funcionaban a tope: A partir de ahora sólo habrá problemas.

Por desgracia en el archivo ducal de Medina Sidonia, no se halla ninguna noticia referente al contrato con Negro porque los legaịos del

(102) Pilar León: op. cit. Doc. n.* 1.720, 1555, enero, 14. Original.

(103) Pilar León:op. cit. Doc. n. 1.724, 1561.

(104) Pilar León: op. cit. Doc. no 1.725, 1565, mayo, 31. Madrid. Copia simple del siglo XVI.

(105) Pilar León: op. cit. Doc. n. $1.726,1565$, julio, 9. El Escorial. Copia simple del siglo xvi, y Doc. n." 1.727, 1568-1574.

(106) Ibidem.

(107) Delumeau: op. cit., pág. 212.

(108) Jbidem, pág. 221.

\section{4}


alumbre que fueron depositados en el archivo del castillo de Mula se deterioraron a consecuencia de la humedad y hoy se hallan algunos en un estado de conservación muy deficiente. Incluso la fecha de iniciación de su contrato es incierta y la hemos fijado a partir de los documentos del ducado de Frías, aunque es posible que fuese unos años antes de 1565 (109). Parece que en el contrato con los genoveses, Felipe II prohibía enviar alumbres a Flandes porque se hallaba en rebeldía frente a la co. rona y los arrendadores tuvieron que vender el alumbre a Inglate rra (110).

Hacia 1568 Felipe II prohibió también enviar alumores a Inglaterra (111). Esta imprudente medida acasionó la ruina del mercado de Anvers. Ello, unido a las guerras de religión en Flandes y en Francia y la importación de los alumbres mediterráneos, marcarán los comienzos de la ruina del alumbre murciano (112).

\section{LA RUINA}

Hacia 1578 los marqueses de Vélez y de Villena arriendan sus haciendas por ocho años al sevillano Diego Sánchez de Córdoba (113). Este personaje se hallaba ya presente en este negocio desde 1574, año en que aparece como "fabriquero" de Mazarrón (114). Efectivamente, en ese año Diego Sánchez Córdoba se compromete al abastecimiento de la fábrica durante seis años, proporcionando ropa, comida y toda clase de pertrechos, pagándole en alumbre los gastos que hiciere en todo ello, a razón de veintiséis reales el quintal (115). Sánchez de Córdoba gastó la bonita suma de 1.523.237 mrs. en pertrechos, ropa y lienzos y 1.666 .635

(109) Ibidem, nota n. 105.

(110) Delumeau: op. cit., pág. 225.

(III) Ibidem, pág. 226.

(112) Ibidem, pág. 281.

(113) A.D.M.S. Legs. 570 y 571.

(114) Ibidem.

(115) Ibidem. 
maravedis en trigo, cebada y carne. Por todo ello, se le entregó 3.242 quintales y cuatro libras de alumbres (116). Al año siguiente proporcionó a la hacienda 5.507 arrobas y 23 libras de harina que montaron 1.040 .997 maravedis; 559 fanegas y 11 celemines de cebada nueva que costaron 209.969 mrs., 155 fanegas y 3 celemines de cebada nueva que costaron 33.223 mrs. y 1.105 arrobas de vino que montaron $201.860 \mathrm{mrs}$. y otras minucias más (117). A cambio de todo ello recibió cuarenta y cinco quintales y veintiuna libras de alumbres (118). Todos estos datos nos descubren la existencia en Mazarrón de una población, ya establecida bastantes años antes, obreros en su mayor parte que vivían en la hacienda con sus familias, y que hacia 1572 cuando pasa a villa ascendía a 479 vecinos (119). El profesor Ruiz Martín da la cifra de 397 pobladores por estos años entre mayordomos, criados y obreros que vivían en las dos haciendas (120). Hemos dicho antes hacieda y, efectivamente, así lo era hasta 1572 que pasa a ser por privilegio de Felipe II la villa de Mazarrón, para lo cual se la separó de la jurisdicción de Lorca a la que pertenecía y se le concedió un término propio (121). Hasta este año fue alcalde, capitán y teniente de Adelantado de Mazarrón el alcalde de la fortaleza de Lorca (122).

La costumbre antes mencionada de pagar deudas y enviar mandas en alumbre era ya frecuente desde los primeros tiempos. Así en 1513 don Pedro Fajardo donó a la viuda de su alcaide en Alhama cuarenta quintales de alumbres por los buenos servicios que le habia hecho (123). Doña Mencia de la Cueva, esposa del primer marqués, dejó en su testamento 100 quintales de alumbre al monasterio de San Francisco de Murcia, 50

(116) A.D.M.S. Legs. 451 y 452 .

(117) Ibidem y leg. 1.163 .

(118) Ibidem.

(119) A.D.M.S. Leg. 33.

(120) Drlumeau: op. cit., pág. 77.

(121) A.D.M.S. Leg. 570.

(122) Ibidem.

(123) A.D.M.S. L.eg. 5.101. 
al de Santo Domingo y 254 para que se vendiesen y con su importe poder rescatar cautivos cristianos de tierra de moros (124).

Hacia 1575 se le entregaron en total a Sánchez de Córdoba 3.070 quintales y 26 libras de alumbres(125). En 1576 el marqués de Vélez, don Pedro II, obtuvo como beneficios de sus alumbres la cantidad de $1.135 .516 \mathrm{mrs}$., deducidos los gastos que se realizaron en ese año de su hacienda (126). Y entre 1579 y 1583 las minas de alumbres proporcionaron todavía a sus propietarios más de veinte millones de maravedís.

¿Qué salarios recibian los obreros de la hacienda? Sobre este aspecto tan sugestivo poseemos por fortuna algủnos datos, aunque, también fragmentarios. Asi en 1592 un guarda de la hacienda ganaba al mes unos $2.040 \mathrm{mrs}$., un destajero $6.800 \mathrm{mrs}$., un atajador $2.250 \mathrm{mrs}$., un mayordomo unos 6.000 mrs., un maestro herrero unos 5.000 y un capacero otros $5.000 \mathrm{mrs}$. (127). Los guardas de la fábrica del alumbre eran nombrados y pagados por ambos señores para evitar el peligro de moros y turcos que de vez en cuando, asolaban las costas de Murcia.

¿Y, cuántos alumbres se fabricaron para conseguir las cantidades antes mencionadas en estos años? Entre el 1 de octubre de 1578 y el 31 de diciembre de 1585 se obtuvieron 43.704 quintales y 48 libras de alumbre, y con los que se fabricaron en 1586, fueron en total 47.095 y 34 libras (128). ¿Y, cuál fue el coste de cada quintal? Desde 1579 hasta 1582 cada quintal de alumbres costaba 12 reales y $18 \mathrm{mrs}$. y entre 1583 y 1585

(124) A.D.M.S. Leg. 5.048.

(125) A.D.M.S. Leg. 1.163 .

(126) Ibidem y leg. 571.

(127) Ibidem. Para defender la costa de los ataques berberiscos los marqueses nombraban y pagaban nueve guardas que hacia 1590 ganaban 20 reales al mes cada uno, otros ocho que solían ponerse cuando habia peligro percibiendo lo mismo que los anteriores, un portero que percibe 75 reales, un requeridor 54 reales, un requeridor 54 reales y 7 atajadores ganando cada uno al mes 36 reales. Cuando cerraron las fábricas los marqueses intentaron que la Corona pagase los sueldos de estas personas.

(128) Ibidem. 
ascendió a 16 reales (129). En 1587 se pagó a 22 reales cada quintal y entre enero y julio de ese mismo año el marqués de Vélez obtuvo de ganancia neta $49.120 \mathrm{mrs}$. por la producción de 2.187 quintales a dos cochas por día, siendo su coste $1.586 .756 \mathrm{mrs}$. (130).

¿Y, la producción anual? En 1576 el veedor Alonso Merino, en nombre de la marquesa doña Mencia de Requesens, tutora del IV marqués don Luis II, vendió a Alonso Sánchez de Sampedro, vecino de Toledo, 1.907 quintales de alumbre, 1.500 de ellos a 25 reales el quintal y los 407 restantes a 24 reales (131). En total Sampedro pagó 47.471 reales por zon; a pesar de ello se puede considerar que tal extensión de tierras, si los alumbres recibidos (132). Sólo sabemos que en 1582 se fabricaron 5.541 quintales que tuvieron de coste $2.674 .402 \mathrm{mrs}$. a $482 \mathrm{mrs}$. cada quintal (133).

En el momento de suscribir el acuerdo con Sánchez de Córdoba. los genoveses habían perdido ya el monopolio del alumbre, no sólo en Murcia, sino también en Tolfa (134). Precisamente este hecho y la dificultad cada vez más creciente de vender grandes cantidades de alumbres en los mercados tradicionales debido a los problemas políticos ya mencionados, fueron los causantes de que las fábricas se entregasen en arriendo, por primera vez de tantos años, a un español.

La hacienda que recibió Sánchez de Córdoba en 1578 se hallaba bastante deteriorada por la explotación tan intensiva que se habia hecho en los últimos años. Las pedreras estaban empezando a agotarse y no se limpiaban, los utensilios se hallaban viejos y en su mayor parte rotos, apenas si se habia interesado por el estado de su hacienda, preocupado no habiendo dinero para repararlos. El tercer marqués, don Pedro II,

(129) Ibidem.

(130) Ibidem.

(131) Ibidem.

(132) Ibidem.

(133) Ibidem.

(134) Delumeau: op. cil., pág. 96. 
únicamente por su carrera política en la Corte, que, al final, le causó la ruina y la muerte tras el desgraciado asunto con Escobedo (135). Su viuda doña Mencia se vio obligada a realizar un inventario de los bienes de su esposo en la hacienda de Mazarrón y es, precisamente, a través de este documento que hemos llegado a la conclusión de que se encontraban en un lamentable abandono (136).

Todo lo que hasta ahora venimos apuntando se va a acelerar aún más en los próximos años. Así, hacia 1586, empieza ya a observarse un cierto siock en la producción, se fabrica más de lo que se vende. La haciendo empieza a almacenar alumbre que no encuentra compradores ni en el extranjera ni en la península, pues los mercaderes y comerciantes de Barcelona y Valencia preferían adquirir alumbre romano (137).

Precisamente y coincidiendo con este hecho, Sánchez de Córdoba, que continúa como arrendador asociado a Beltrán de Sampedro y Damián de Bolea, se queja de que la hacienda se encuentra en mal estado y que las minas se hallan casi consumidas y tan llenas de tierra y piedras que para limpiarlas tienen necesidad de muchos mrs. de gastos (138).

La decadencia es ya un hecho a partir de 1588 en que la fábrica apenas si producía ya 3.000 quintales por falta de consumo del alumbre, a causa de las guerras con Flandes e Inglaterra y el crecido costo de sus canteras, por lo que parecía arriesgada la empresa de instalar nuevas fábricas cuando se iban arruinando las antiguas (139). Ni siquiera esa

(135) Gregorio Marañón: Los Tres Vélez, Madrid, 1962.

(136) A.D.M.S. Leg. 570. Este inventario recoge todos los bienes que los Fajardo poseian en la villa de Mazarrón y que son los siguientes: una iglesia dedicada a San Antonio de Padua, fundada por el primer marqués, catorce casas y una caballeriza vieja, más de cuarenta pedreras de minas en las que se obtiene el alumbre y todas las armas y pertrechos que habia en la fortaleza. En la iglesia se hallan varios retablos que representan a San Antonio, la Virgen y los tres Reyes, San Cosme y Damián, Nuestra Señora del Rosario, la Virgen con Jesús en los brazos y Nuestra Señora de la Concepción.

(137) Delumeau: op. cit., pág. 282. A.D.M.S. Leg. 33.

(138) A.D.M.S. Leg. 1.163.

(139) A.D.M.S. Leg. 570. 
cantidad podía ya venderse. El negocio del alumbre empieza, pues, a no interesar ya y los marqueses se decidieron muy pronto a abandonarlo. Villena, según Delumeau, acumuló entre 1583 y 1586 entre 100.000 y 150.000 quintales, que, al parecer, no habian sido vendidos hacia 1590 (140). A todo ello se unía el pleito que la Real Hacienda había puesto a Villena y a Vélez sobre el pago de los derechos de alcabala y almojarifazgo de todos los alumbres que desde 1575 se habían producido en Mazarrón y habían sido llevados fuera del reino. El fiscal pedía más de $\mathbf{8 0 . 0 0 0}$ ducados por todo ello y exigía que los alumbres no disfrutasen en lo sucesivo de esa libertad como hasta ese momento habian gozado (141). Esta contrariedad se sumaba a las anteriores y todas ellas fueron las causas que precipitaron el desenlace final de su total liquidación unos años más tarde.

En 1589 se hallaron en la fábrica 11.256 arrobas y 5 libras de alumbre pertenecientes al marqués de Vélez (142). Desde este año ya no aparece como arrendador Sánchez de Córdoba y a partir de ese momento las fábricas quedan en poder de sus dueños que recurren al capitán Julián y a Ginés Hernández Quesada para que en encarguen de la producción de las mismas (143). Entre 1589 y 1592 se obtuvieron 11.465 quintales y 80 libras de alumbres. En 1590 la fabricación fue de 2.953 quintales y 18 libras a razón cada quintal de 35 reales (144).

A fines de 1592 las fábricas de alumbre cerraron definitivamente porque en España apenas si había consumo y los compradores eran los Países Bajos e Inglaterra, con los que la Monarquía estaba en guerra. Felipe Ruiz Martín ha diagnosticado con acierto la causa fundamental de esta quiebra que fue la excesiva fiscalidad de Felipe II que impuso en 1590 la contribución de los millones, no sólo sobre los campesinos,

(140) Delumeau: op. cit., pág. 283.

(141) A.D.M.S. Leg. 571 .

(142) A.D.M.S. Legs. 451 y 452. Parece que algunos de los obreros que trabajaban por estos años eran esclavos del marqués de Vélez. A.D.M.S. Leg. 1.307.

(143) A.D.M.S. Leg. 571.

(144) A.D.M.S. Leg. 451 . 
sino también sobre los privilegiados (145). A ello se unió además la decadencia de la industria textil flamenca. Las minas de Rodalquilar se habian cerrado ya dos años antes (146).

Los alumbres se fueron amontonando en los almacenes y no pudieron venderse sino en pequeñas partidas a un precio infimo y al fiado. Así, en 1596 se hallaban en la hacienda de Vélez 7.360 quintales y 62 libras todavia sin vender (147). Hacia 1606, una vez firmadas las paces con Inglaterra, volvieron a abrirse las fábricas, pero ya era imposible volver atrás, porque el negocio había decaído considerablemente y no era rentable (148). Desde esta fecha, comenzó a producirse almagra que se vendía mejor. En realidad, la almagra venía obteniéndose desde 1579 y a partir del cierre del alumbre venía produciéndose en grandes cantidades.

¿Qué quedaba, pres, de ambas haciendas al término de una centuria que tantas ambiciones había visto desatarse por la cuestión de ese discretísimo personaje que fue el alumbre? Ruina, abandono, pérdidas y poco más es lo que hallamos en esos parajes costeros que durante mucho tiempo habian producido grandes beneficios a sus propietarios. Una posibilidad industrial más de la corona castellana se perdió definitivamente como se habian pérdido muchas otras anteriormente. Un pueblo, Mazarrón, una iglesia, la de San Antonio, fundada por el primer marqués, y unos pobres vecinos que quedaban sin saber qué hacer pues, hasta ese momento, de lo único que habian vivido había sido del alum. bre, producto éste que había sido precisamente el que había creado esa villa y sus gentes. Ante la incertidumbre de un negro futuro, el Concejo de Mazarrón suplicó al marqués de Vélez que le remediase sus males puesto que no sabían qué iban a hacer sin fabricar alumbres, que la villa tenía muy pocos propios de los que poder vivir, que el lugar iba a despoblarse, qué quien les iba a defender ahora, que depositaban toda

(145) Delumeau: op. cit., págs. 39 y 282.

(146) Ibidem.

(147) A.D.M.S. Leg. 571.

(148) A.D.M.S. Leg. 33. 
su confianza en su persona. La respuesta no pudo ser más contundente y concisa, el marqués les comunica que nada puede hacer, que la fábrica ha tenido que cerrarla porque lleva años produciéndole pérdidas y ello era lo único que a su hacienda interesaba (149). Una respuesta tan brutal, tan sincera y tan falta de escrúpulos ponía punto final a una de las empresas mineras más importantes de la península Ibérica en el siglo xvi.

(149) A.D.M.S. Leg. 5.101.

\section{2}

